\title{
Predicting the Resolution of Type 2 Diabetes after Bariatric Surgical Procedures: A Concise Review
}

\author{
Min $\mathbf{T}^{1}$, Barry $\mathbf{J D}^{2}$ and Stephens $\mathbf{J W}^{1,2,3 *}$ \\ ${ }^{1}$ Department of Diabetes and Endocrinology, Morriston Hospital ABM University Health Board, Swansea SA6 6NL, UK \\ ${ }^{2}$ Welsh Institute of Metabolic and Obesity Surgery, Morriston Hospital ABM University Health Board, Swansea SA6 6NL, UK \\ ${ }^{3}$ Diabetes Research Group, Institute of Life Sciences, Swansea University, Swansea SA2 8PP, UK
}

*Corresponding author: Professor Jeffrey W Stephens, Diabetes Research Group, Institute of Life Sciences, Swansea University, Swansea SA2 8PP, UK, Tel: +440-1792 704078; Fax: +440-1792 703214; E-mail: J.W.Stephens@Swansea.ac.uk

Rec date: Sep 28, 2015; Acc date: Oct 14, 2015; Pub date: Oct 19, 2015

Copyright: (C) 2015 Min T, et al. This is an open-access article distributed under the terms of the Creative Commons Attribution License, which permits unrestricted use, distribution, and reproduction in any medium, provided the original author and source are credited.

\begin{abstract}
Bariatric surgery has become an established evidence-based treatment option for diabetes associated with obesity. Numerous studies have demonstrated that bariatric surgery is superior to conventional medical treatment and is effective in achieving resolution of hyperglycaemia or improvement in glycaemic control in type 2 diabetes. However, diabetes remission after bariatric surgery does not occur universally in patients and surgical procedures are associated with the risks of complications. It is imperative to identify patients who are likely to gain the best possible metabolic benefit i.e. resolution of diabetes from bariatric surgery. Several clinical and biochemical factors have been studied to predict diabetes remission following bariatric surgery. This article provides a concise review within this area and describes the available scoring systems to predict diabetes remission.
\end{abstract}

Keywords: Bariatric surgery; Diabetes resolution; Glycaemic control

\section{Introduction}

In 2008, the World Health Organisation described that 1.4 billion people were overweight and more than 0.5 billion were obese. These figures are estimated to rise to 2.3 billion and 0.7 billion by 2015 [1]. At least 2.8 million people die each year as a consequence of obesity related mortality [1]. Obesity is strongly associated with diabetes, cardiovascular diseases and cancers.

Globally, $44 \%$ of diabetes, $23 \%$ of ischaemic heart disease and $7-41 \%$ of cancers are attributable to being overweight and obesity [1]. In the United Kingdom (UK) in 2012, 62\% of adults were overweight, with $25 \%$ being obese [2]. The UK prevalence of diabetes in adults was $6 \%$ in 2013 [3] and 90\% of adults with type 2 diabetes (T2DM) are overweight or obese. The parallel rise in the prevalence of both obesity and T2DM has become a major health problem.

Metabolic (bariatric) surgery has become an established evidencebased treatment option for obesity related T2DM. International and national guidelines support this therapeutic approach for people with $\mathrm{T} 2 \mathrm{DM}$ and a body mass index $(\mathrm{BMI}) \geq 35 \mathrm{~kg} / \mathrm{m}^{2}$. Bariatric surgical procedures include laparoscopic adjustable gastric banding (LAGB), Roux-en-Y gastric bypass (RYGB), sleeve gastrectomy (SG), biliopancreatic diversion (BPD) and duodenal switch (DS). Numerous studies have shown that bariatric surgery is superior to conventional medical treatment, and moreover is effective in achieving remission of T2DM $[4,5]$. However, the resolution of T2DM following metabolic surgery is not universal.

The Swedish Obese Subjects Study data showed that the remission of diabetes was $72 \%$ at 2 years and $36 \%$ at 10 years [4]. The second National Bariatric Surgery Register (NBSR) report showed an $80 \%$ remission at 3 years following bariatric surgery [5]. In addition, whilst bariatric surgery is associated with a low morbidity and mortality [5], all the surgical interventions except LAGB are generally accepted to be irreversible, invasive and carry risks.

Controversy and lack of clarity exists within published data relating to the preoperative clinical or biochemical measurements which might predict T2DM resolution [6]. A robust prediction model might support the bariatric multidisciplinary team in identifying the most suitable patient for surgery and the appropriate surgical procedure. Within the UK and other parts of the world, metabolic surgery remains rationed as a consequence of funding difficulties, lack of experienced staff and other challenges, and therefore a clinical tool to predict diabetes outcome is desirable.

\section{Factors Predicting Remission of Type 2 Diabetes Following Bariatric Surgery}

Several clinical and biochemical factors have been proposed as predictors of T2DM resolution after weight loss surgery, as summarised in Table 1.

\begin{tabular}{|l|l|}
\hline Clinical predictors & Biochemical predictors \\
\hline Age & $\begin{array}{l}\text { Glycaemic control: Fasting blood } \\
\text { glucose and HbA1c } \\
\text { BMI }\end{array}$ \\
Duration of T2DM & C-peptide level \\
Severity of T2DM & \\
\hline BMI: body mass index; T2DM; type 2 diabetes \\
\hline
\end{tabular}

Table 1: Pre-operative predictors of diabetes remission after bariatric surgery 


\section{Clinical predictors}

1. Age: Age is an important consideration in patient selection for bariatric surgery [7]. Increasing age is not only associated with higher perioperative and postoperative complications but is also less successful with respect to weight loss [8,9]. Previous studies have shown that younger age is associated with both early and late remission of T2DM following surgery [10-13]. However, this may be debatable [7]. Still et al., studied 690 patients and observed that each 10 -year decrease in age was associated with a greater odds ratio (OR) of early $(1.41[1.10-1.80], \mathrm{p}=0.0071)$ and later remission of T2DM (1.45 [1.10-1.92], $\mathrm{p}=0.0085)$ [14]. Hamza et al., also observed that younger age was an independent predictor of postoperative T2DM remission [13]. Similar findings have also been observed by Huang et al., in a study of 22 Chinese patients with a BMI between $25-35 \mathrm{~kg} / \mathrm{m}^{2}$ [12]. Furthermore, a German study found that increasing age was an independent significant predictor for postoperative metabolic failure [10]. These observations were confirmed by a recently published metaanalysis of 13 studies $(\mathrm{n}=1149)$ which showed a significant negative association between preoperative age and T2DM remission (OR: -2.46 [-3.90 to -1.02$], \mathrm{p}<0.01)$ [15].

2. Body Mass Index: Visceral obesity has a strong association with insulin resistance and T2DM [16] and hence weight loss improves insulin sensitivity and T2DM. However, it is now evident from the published literature that improvements in insulin and glucose homeostasis are observed soon after SG, RYGB and BPD. Therefore it may be argued that improved glycaemic control occurs before significant weight loss. Several explanations have been provided for this phenomenon including effects on the incretin response, changes in ghrelin and other gut hormones and improved hepatic insulin sensitivity [17]. Furthermore significant early changes have been observed in adipose related cytokines such as interleukin-6, leptin and C-reactive protein, all of which have effects to induce insulin resistance [18]. However, we cannot generalise that obesity and T2DM always occur together. Clearly not all people with T2DM are obese and not all obese people have T2DM [2]. T2DM is a complex heterogeneous condition with differing pathophysiological contributions from insulin resistance, excess hepatic glucose release and pancreatic beta cell dysfunction [19]. Therefore, individuals with increased susceptibility to develop T2DM at a lower BMI might produce less insulin or might become insulin resistant with only minimal weight gain. The majority of the current guidelines recommend bariatric surgery in whitecaucasian individuals with $\mathrm{BMI} \geq 35 \mathrm{~kg} / \mathrm{m}^{2}$ and T2DM [20,21]. The most recent NICE guideline recommend that assessment for bariatric surgery for South Asian individuals should be at a lower BMI than other populations [20].

Several studies have found a higher preoperative BMI is associated with better T2DM resolution following surgery. Of interest, DiGiorgi et al., found that patients with a re-occurrence of T2DM or a deterioration in glycaemic control following surgery was associated with a lower baseline BMI (47.9 v $\left.52.9 \mathrm{~kg} / \mathrm{m}^{2}, \mathrm{p}=0.05\right)$ [22]. Similar findings have been observed in Asian samples [11,23]. Dixon et al. observed that patients with a preoperative $\mathrm{BMI}>35 \mathrm{~kg} / \mathrm{m}^{2}$ had higher rate of diabetes remission compared to those with a BMI $<35 \mathrm{~kg} / \mathrm{m}^{2}$ [11]. Furthermore, in a Chinese study of subjects with T2DM and a BMI $<30 \mathrm{~kg} / \mathrm{m}^{2}$, the glycaemic response to RYGB was predicted by higher baseline BMI [23]. Interestingly, in a recently published metaanalysis, waist circumference rather than BMI was the only significant predictor [24]. Panunzi et al., observed similar T2DM remission in two groups with a BMI $<35 \mathrm{~kg} / \mathrm{m}^{2}$ and a BMI $>35 \mathrm{~kg} / \mathrm{m}^{2}$ [24]. Other studies found that a super-obese BMI was not a good predictor of T2DM resolution [25] and may be associated with reduced life expectancy [26]. Robert et al., showed that a baseline BMI $<50 \mathrm{~kg} / \mathrm{m}^{2}$ had $70 \%$ sensitivity and $80 \%$ specificity $(\mathrm{p}=0.001)$ to predict $\mathrm{T} 2 \mathrm{DM}$ at one year [27]. A recently published study found that bariatric surgery may reduce life expectancy in an individual with diabetes with BMI > $62 \mathrm{~kg} / \mathrm{m}^{2}[26]$.

3. Duration of Diabetes: Progressive pancreatic beta cell failure is a typical feature of T2DM and progresses with diabetes duration [19]. The remission of T2DM following bariatric surgery is dependent on beta cell function to synthesise and release insulin [28]. Furthermore, a substantial proportion of individuals may have asymptomatic or undiagnosed T2DM, or impaired glucose tolerance for many years prior to diagnosis. This is supported by the International Diabetes Federation (IDF) estimate that 175 million people worldwide have undiagnosed diabetes [29]. This will therefore lead to challenges in reliably knowing the duration of T2DM. Within the available literature, the duration of diabetes is consistently described as a prognostic factor for T2DM remission. However, there appears to be little consensus in relation to cut-off value for the duration of diabetes. Most studies recommend a cut-off value of between 4-8 years as an independent prognostic value for diabetes remission [9-11,23,27,30]. Pories et al., observed that patients with good metabolic response had a shorter duration of diabetes $(1.75 \pm 0.69$ vs. $8.79 \pm 2.8$ years) [9]. Schauer et al., replicated similar findings and showed that patients with a diabetes duration $<5$ years had a greater chance of complete remission after gastric bypass surgery [30]. Robert et al., demonstrated that a duration $<4$ years had a $79 \%$ sensitivity and $80 \%$ specificity $(\mathrm{p}=0.0001)$ to predict resolution at one year [27]. In a study by Casella et al., a 10year cut-off in diabetes duration yielded a $75 \%$ sensitivity and $96 \%$ specificity for diabetes remission after SG [31]. Of interest, within the UK, the most recent NICE guidance on obesity has been updated so that consideration of bariatric surgery should be made in patients with recently diagnosed diabetes and BMI between $30-35 \mathrm{~kg} / \mathrm{m}^{2}$ [20].

4. Severity of Type 2 Diabetes: As described previously, the remission of T2DM depends on the degree of beta cell dysfunction and duration of diabetes. The requirement of diabetes medications to control hyperglycaemia might therefore reflect on the severity of T2DM. Different guidelines recommend different treatment algorithms and some recommend early insulin use [21,32]. The duration of undiagnosed diabetes will also necessitate more rapid progression to insulin therapy. The initiation of insulin treatment in T2DM typically occurs when there is failure of oral therapies. This failure is the result of beta cell exhaustion so that the oral agents are no longer effective in promoting insulin release [19]. In the DiaRem Score study, the use of insulin therapy prior to surgery is one of four variables predicting diabetes remission. This showed that $90.1 \%$ (95\% CI: $86.6-93.6 \%$ ) of patients who had not been on insulin prior to surgery had achieved remission after 5 years, compared with $31.1 \%$ (23.5-38.6\%) of those receiving insulin [14]. Robert et al., also demonstrated that non-insulin based therapies was an independent predictor for remission one year after surgery (AUC ROC 0.858, $\mathrm{p}=0.0001$, sensitivity $96 \%$ and specificity 60\%) [27]. Similarly, Blackstone et al., observed that the remission rates were greater for 505 patients not using insulin pre-operatively $(53.8 \%$ v $13.5 \%, \mathrm{p}<0.001)$ [33]. In a study of 130 subjects, $100 \%$ of patients who had previously unrecognised diabetes or diet control T2DM achieved remission after one year, compared with $93 \%$ of those on oral hypoglycaemic agents and $50 \%$ of those receiving insulin [34]. 


\section{Biochemical predictors}

1. Glycaemic control prior to metabolic surgery: Fasting blood glucose and HbA1c: Chronic hyperglycaemia has a detrimental effect on pancreatic beta cell function and number. Glucotoxicity leads to beta cell apoptosis, subsequent insulin hyposecretion, elevated blood glucose levels and finally further progressive beta cell decline [35]. Therefore the beta cells become desensitised, exhausted and apoptotic. With the normalisation of blood glucose level, beta cells recovery is a possibility [36] and hence good glycaemic control results in a higher probability of beta cell recovery. Lower plasma levels of fasting blood glucose and $\mathrm{HbAlc}$ are associated with a greater probability of T2DM remission following surgery. In a study of 127 patients with T2DM, Hayes et al., [34] showed that lower levels of fasting blood glucose and HbA1c were markers for T2DM remission after gastric bypass surgery. The strongest negative predictor was a high $\mathrm{HbAlc}$ and requirement of insulin treatment. Similarly, Robert et al., [27] concluded that a fasting glucose $<114 \mathrm{mg} / \mathrm{dL}$ and a HbAlc $<7.1 \%$ were predictors for T2DM resolution at one year, regardless of the type of bariatric operations. In a study by Jurowich et al. [10], 17 out of 82 participants did not show an improvement in their diabetes with non responders having a higher preoperative HbAlc level (8.34\% vs. $7.78 \%$, $\mathrm{p}=0.033$ ). In the DiaRem score [14] preoperative HbAlc was one of four scoring criteria. Higher HbAlc level was associated with a higher hazard ratio for persisting diabetes. The hazard ratios for HbAlc ranges 6.5-5.9\%, 7-8.9\% and $\geq 9 \%$ were 1.46 [1.12-1.89], $\mathrm{p}=0.0045,2.51$ [1.96-3.23], $\mathrm{p}<0.0001$ and 3.35 [2.24-5.03], $\mathrm{p}<0.0001$ respectively. Short-term (over six months) glycaemic improvement prior to bariatric surgery has a significant impact on the metabolic outcome postoperatively. In a study of 245 diabetes patients undergoing RYGB, preoperative tight blood glucose control resulted in a $58 \%$ greater chance of remission [7].

2. C-peptide level: C-peptide is a 31-amino acids peptide, produced during cleavage of insulin from pro-insulin in the pancreatic beta cells [37]. C-peptide and insulin are released in equimolar amounts from pancreatic beta cells into the portal circulation. Both insulin and Cpeptide levels are biologic markers of pancreatic beta cell function, but C-peptide is a better proxy for estimating beta cell reserve, because of its longer half-life and renal clearance. Endogenous insulin concentrations may also be high in obese individuals with insulin resistance. In addition, measurement of endogenous insulin may be affected by exogenous insulin and anti-insulin-antibodies especially in those treated with insulin [38]. Therefore, C-peptide may be a better surrogate marker for pancreatic beta cell reserve and an index of endogenous insulin secretion. As already discussed, T2DM is complex and the pathophysiology is a result of both insulin resistance and beta cell dysfunction. Remission of T2DM following surgery depends on the baseline beta cell function. Studies by Dixon et al., demonstrated that fasting C-peptide measurement preoperatively was a good predictor in Asian populations [11,23]. A fasting C-peptide $>2.9 \mathrm{ng} / \mathrm{mL}$, a diabetes duration $<4$ years and $\mathrm{BMI}>35 \mathrm{~kg} / \mathrm{m}^{2}$ were independent predictors for T2DM resolution at 12 months. A similar finding was observed by Ramos-Levi et al. [39], where pre-operative C-peptide levels were higher in those achieving remission at one year. C-peptide measurements also have a role in predicting T2DM resolution at 3 years following bariatric surgery. In a study of 29 participants with impaired glucose tolerance and 56 with T2DM, 90\% of T2DM patients with a preoperative fasting C-peptide value $>1.0 \mathrm{nmol} / \mathrm{L}(3.0 \mathrm{ng} / \mathrm{mL})$ achieved a postoperative $\mathrm{HbAlc}<6.5 \%$ and $74 \%$ achieved complete resolution after $3.6 \pm 0.16$ years follow-up [40]. A meta-analysis of 142 patients with T2DM in two Asian studies showed a significant association between preoperative C-peptide levels and remission $(\mathrm{OR}=0.62[0.33-0.91], \mathrm{P}<0.01)[15]$.

\section{Scoring systems}

Several scoring systems have been developed in an attempt to predict T2DM remission following metabolic surgery. However, these scoring systems are not designed for all bariatric surgical procedures and are not validated across all population. For instance, the DiaRem score is designed for RYGB [34]; the Indian Diabetes Remission score is based on a local population [41]; and the ABCD scoring system is only validated for an Asian population who have a different phenotype of T2DM (lower BMI) compared to Western populations [42,43].

\section{The DiaRem score}

\begin{tabular}{|l|l|}
\hline Age (years) & Score \\
\hline$<40$ & 0 \\
\hline $40-49$ & 1 \\
\hline $50-59$ & 2 \\
\hline$\geq 60$ & 3 \\
\hline HbA1c & 0 \\
\hline$<6.5 \%$ & 2 \\
\hline $6.5-6.9$ & 4 \\
\hline $7-8.9$ & 6 \\
\hline$\geq 9$ & 0 \\
\hline $\begin{array}{l}\text { Other diabetes drugs } \\
\text { remission following RYGB surgery }\end{array}$ & 10 \\
\hline $\begin{array}{l}\text { No SU or Insulin-sensitising agent } \\
\text { other than metformin }\end{array}$ & 0 \\
\hline $\begin{array}{l}\text { SU or Insulin-sensitising agent other } \\
\text { than metformin }\end{array}$ & 3 \\
\hline Treatment with insulin & with a greater likelihood of diabetes \\
\hline No & 0 \\
\hline Yes & 0 \\
\hline SU: & 0 \\
\hline
\end{tabular}

Table 2: The DiaRem Score [34]

Still and colleagues have described this scoring system to predict probability of diabetes remission following RYGB [14]. The scoring system consists of four preoperative clinical variables: age, HbAlc, insulin use, and type of diabetes medications (Table 2). The score ranges from $0-22$, with the greatest emphasis being on insulin use preoperatively. A lower DiaRem score is associated with a greater likelihood of diabetes remission following RYGB surgery. Within the study, $88 \%$ of patients who scored $0-2$ achieved diabetes remission, whilst $2 \%$ of those who scored $18-22$ did. Of note, they also observed that preoperative use of incretin mimetic improved the likelihood of diabetes remission postoperatively. 
Page 4 of 5

\section{The ABCD Diabetes Surgery score}

Lee et al., proposed a scoring system comprising of age, BMI, Cpeptide and duration of diabetes. The initial score was designed for RYGB surgery (Table 3) [43] and then modified for SG (Table 4) [42]. The Diabetes Surgery score for RYGB was validated in 176 Asian patients [43].

\begin{tabular}{|l|l|l|l|l|}
\hline Variables & \multicolumn{4}{|l|}{ Diabetes Surgery Score } \\
\hline & 0 & 1 & 2 & 3 \\
\hline Age & $\geq 40$ & $<40$ & & \\
\hline BMI & $<30$ & $30-39$ & $40-49$ & $>50$ \\
\hline C-peptide $(\mathrm{ng} / \mathrm{mL})$ & $0.9-1.9$ & $2.0-3.9$ & $4-6$ & $>6$ \\
\hline Duration of diabetes & $>10$ & $5-10$ & $2-4.9$ & $<2$ \\
\hline RYGB: Roux-en-Y gastric bypass; BMI: body mass index
\end{tabular}

Table 3: Diabetes Surgery Score (RYGB) [43]

Remission of T2DM was defined as a fasting blood glucose $<110$ $\mathrm{mg} / \mathrm{dL}$ and $\mathrm{HbAlc}<6 \%$ without the use of anti diabetic drugs or insulin. A total of 115 remissions (65.3\%) were observed one year after RYGB. Patients with T2DM remission after surgery had a greater Diabetes Surgery Score than those without $(8 \pm 4$ vs. $4 \pm 4, \mathrm{p}<0.05)$. Patients with a greater Diabetes Surgery Score also had a greater rate of success of T2DM remission (from $33 \%$ at score 0 to $100 \%$ at score $\geq 8$ ).

\begin{tabular}{|l|l|l|l|l|}
\hline Variables & \multicolumn{4}{|l|}{ Diabetes Surgery Score } \\
\hline & 0 & 1 & 2 & 3 \\
\hline Age & $\geq 40$ & $<40$ & & \\
\hline BMI & $<27$ & $27-34.9$ & $35-41.9$ & $>42$ \\
\hline C-peptide $(\mathrm{ng} / \mathrm{mL})$ & $<2$ & $2.0-2.9$ & $3-4.9$ & $>5$ \\
\hline Duration of diabetes & $>8$ & $4-8$ & $1-3.9$ & $<1$ \\
\hline
\end{tabular}

LSG: laparoscopic sleeve gastrectomy; BMI: body mass index

A higher Diabetes Surgery score is associated with a greater likelihood of diabetes remission following bariatric surgery

Table 4: Diabetes Surgery Score (LSG) [42]

A 1-point increment in the Diabetes Surgery Score translated to an absolute $6.7 \%$ in the success rate. The modified ABCD Diabetes Surgery Score was validated in 85 Asian patients undergoing LSG [42]. At 12 months following LSG, 52.9\% had complete remission (HbA1c $<6.0 \%$ ) and $21.2 \%$ had partial remission (HbAlc $<6.5 \%$ ). Responders had a higher $\mathrm{ABCD}$ score than non-responders (7.3 \pm 1.7 vs. $5.2 \pm 2.1$, $\mathrm{p}<0.05)$. Patients with a higher ABCD score also had higher T2DM remission ( $0 \%$ in score 0 to $100 \%$ in score 10$)$.

\section{The Diabetes Remission Score}

An Indian study [41] reported a Diabetes Remission Score (DRS) for two bariatric surgical procedures: Ileal Interposition coupled with Sleeve Gastrectomy (IISG) $(\mathrm{n}=46)$ and Diverted Sleeve Gastrectomy (IIDSG) $(\mathrm{n}=29)$ (Table 5). The scoring system used 7 parameters: age, BMI, duration of diabetes, microvascular complications, macrovascular complications, preoperative insulin use, and stimulated
C-peptide. They concluded that the score was significantly lower in patients with remission than those without remission. Patients with a DRS $\geq 10$ in IISG group and more than 12 in IIDSG group did not get into remission.

\begin{tabular}{|l|l|l|}
\hline Parameters & \multicolumn{2}{l|}{ Diabetes Remission Score } \\
\hline & 1 & 2 \\
\hline Age (years) & $30-60$ & $<30$ or $>60$ \\
\hline BMI & $\geq 27$ & $<27$ \\
\hline Duration of diabetes & $<10$ & $>10$ \\
\hline Microvascular complications & No & Yes \\
\hline Macrovascular complications & No & Yes \\
\hline Preoperative insulin use & No & Yes \\
\hline $\begin{array}{l}\text { Stimulated C-peptide } \\
\text { BMl: body mass index }\end{array}$ & $\geq 4$ & $<4$ \\
\hline $\begin{array}{l}\text { A lower Diabetes remission score is associated with a greater chance of } \\
\text { diabetes remission following bariatric surgery }\end{array}$
\end{tabular}

Table 5: Diabetes Remission Score [41]

\section{Conclusion}

Bariatric surgery is an effective treatment option for obesity associated T2DM. Patient selection is important to optimise maximal benefit with minimal adverse outcomes. Preoperative clinical and biochemical factors that could predict the outcome of T2DM following bariatric surgery would be useful for the bariatric multidisciplinary team. It may be impossible to identify the most important single predictor as most of the clinical and biochemical predictive factors described above are inter-related to one another. For example a longer duration of diabetes is associated with increasing age; the need for insulin therapy is associated with a long duration of diabetes; a long duration of diabetes and poor glycaemic control is associated with poor pancreatic beta cell reserve. A simple, but robust diabetes surgery scoring system that could be applicable to all type of bariatric surgical procedures and across the population is needed. Furthermore, most of the studies investigating predictors have examined diabetes resolution at 12-14 months postoperatively. Further studies investigating longer term outcome i.e. 5 years and above are needed as well. Furthermore further investigation is required examining the resolution of T2DM following surgery in different ethnic groups. Of note there is paucity in the published literature examining this in Latino and AfricanAmerican patients.

\section{References}

1. WHO (2014) 10 facts on obesity.

2. Gatineau M, Hancock C, Holman N, Outhwaite H, Oldridge L, et al. (2014) Adult obesity and Type 2 diabetes. Public Health, England.

3. Diabetes UK (2014) Diabetes: Facts and Stats. Version 3. 2014.

4. Sjöström L, Lindroos AK, Peltonen M, Torgerson J, Bouchard C, et al. (2004) Lifestyle, diabetes, and cardiovascular risk factors 10 years after bariatric surgery. N Engl J Med 351: 2683-2693.

5. NBSR (2014) The National Bariatric Surgery Registry of the British Obesity and Metabolic Surgery society: Second registry report. 
6. Rubino F, Kaplan LM, Schauer PR, Cummings DE; Diabetes Surgery Summit Delegates (2010) The Diabetes Surgery Summit consensus conference: recommendations for the evaluation and use of gastrointestinal surgery to treat type 2 diabetes mellitus. Ann Surg 251: 399-405.

7. $\quad$ English TM, Malkani S, Kinney RL, Omer A, Dziewietin MB, et al. (2015) Predicting Remission of Diabetes After RYGB Surgery Following Intensive Management to Optimize Preoperative Glucose Control. Obes Surg. 25: 1-6.

8. Ramanan B, Gupta PK, Gupta H, Fang X, Forse RA (2012) Development and validation of a bariatric surgery mortality risk calculator. J Am Coll Surg 214: 892-900.

9. Pories WJ, MacDonald KG Jr, Morgan EJ, Sinha MK, Dohm GL, et al. (1992) Surgical treatment of obesity and its effect on diabetes: $10-y$ follow-up. Am J Clin Nutr 55: 582S-585S.

10. Jurowich C, Thalheimer A, Hartmann D, Bender G, Seyfried F, et al. (2012) Improvement of type 2 diabetes mellitus (T2DM) after bariatric surgery--who fails in the early postoperative course? Obes Surg 22: 1521-1526.

11. Dixon JB, Chuang LM, Chong K, Chen SC, Lambert GW, et al. (2013) Predicting the glycemic response to gastric bypass surgery in patients with type 2 diabetes. Diabetes Care 36: 20-26.

12. Huang CK, Shabbir A, Lo CH, Tai CM, Chen YS, et al. (2011) Laparoscopic Roux-en-Y gastric bypass for the treatment of type II diabetes mellitus in Chinese patients with body mass index of 25-35. Obes Surg 21: 1344-1349.

13. Hamza N, Abbas MH, Darwish A, Shafeek Z, New J, et al. (2011) Predictors of remission of type 2 diabetes mellitus after laparoscopic gastric banding and bypass. Surg Obes Relat Dis 7: 691-696.

14. Still CD, Wood GC, Benotti P, Petrick AT, Gabrielsen J, et al. (2014) Preoperative prediction of type 2 diabetes remission after Roux-en-Y gastric bypass surgery: a retrospective cohort study. Lancet Diabetes Endocrinol 2: 38-45.

15. Wang GF, Yan YX, Xu N, Yin D, Hui Y, et al. (2015) Predictive factors of type 2 diabetes mellitus remission following bariatric surgery: a metaanalysis. Obes Surg 25: 199-208.

16. Carey DG, Jenkins AB, Campbell LV, Freund J, Chisholm DJ (1996) Abdominal fat and insulin resistance in normal and overweight women: Direct measurements reveal a strong relationship in subjects at both low and high risk of NIDDM. Diabetes 45: 633-638.

17. Mallipedhi A, Prior SL, Barry JD, Caplin S, Baxter JN, et al. (2014) Temporal changes in glucose homeostasis and incretin hormone response at 1 and 6 months after laparoscopic sleeve gastrectomy. Surg Obes Relat Dis. 10: 860-9.

18. Mallipedhi A, Prior SL, Barry JD, Caplin S, Baxter JN, et al. (2014) Changes in inflammatory markers after sleeve gastrectomy in patients with impaired glucose homeostasis and type 2 diabetes. Surg Obes Relat Dis. 10: 1123-8.

19. DeFronzo RA, Cersosimo E, Mandarino LJ (2015) Pathogenesis of Type 2 Diabetes Mellitus.

20. NICE (2014) Obesity: identification, assessment and management of overweight and obesity in children, young people and adults.

21. ADA Section 7 (2015) Approaches to glycaemic targets. Standards of medical care in diabetes: 2015. Diabetes Care. 38: S41-8.

22. DiGiorgi M, Rosen DJ, Choi JJ, Milone L, Schrope B, et al. (2010) Reemergence of diabetes after gastric bypass in patients with mid- to longterm follow-up. Surg Obes Relat Dis. 6: 249-53.

23. Dixon JB, Hur KY, Lee WJ, Kim MJ, Chong K, et al. (2013) Gastric bypass in Type 2 diabetes with BMI < 30: weight and weight loss have a major influence on outcomes. Diabet Med. 30: e127-34.
24. Panunzi S, De Gaetano A, Carnicelli A, Mingrone G (2014) Predictors of Remission of Diabetes Mellitus in Severely Obese Individuals Undergoing Bariatric Surgery: Do BMI or Procedure Choice Matter? A MetaAnalysis. Ann Surg. 261: 459-467.

25. Arterburn DE, Bogart A, Sherwood NE, Sidney S, Coleman KJ, et al. (2013) A multisite study of long-term remission and relapse of type 2 diabetes mellitus following gastric bypass. Obes Surg. 23: 93-102.

26. Schauer DP, Arterburn DE, Livingston EH, Coleman KJ, Sidney S, et al. (2015) Impact of Bariatric Surgery on Life Expectancy in Severely Obese Patients With Diabetes: A Decision Analysis. Ann Surg. 261: 914-9.

27. Robert M, Ferrand-Gaillard C, Disse E, Espalieu P, Simon C, et al. (2013) Predictive factors of type 2 diabetes remission 1 year after bariatric surgery: impact of surgical techniques. Obes Surg. 23: 770-5.

28. Nannipieri M, Mari A, Anselmino M, Baldi S, Barsotti E, et al. (2011) The role of beta-cell function and insulin sensitivity in the remission of type 2 diabetes after gastric bypass surgery. J Clin Endocrinol Metab. 96: E1372-9.

29. International Diabetes Federation (2013) IDF Diabetes Atlas (6th edn) Brussels, Belgium: International Diabetes Federation.

30. Schauer PR, Burguera B, Ikramuddin S, Cottam D, Gourash W, et al. (2003) Effect of laparoscopic Roux-en Y gastric bypass on type 2 diabetes mellitus. Ann Surg. 238: 467-84.

31. Casella G, Abbatini F, Cali B, Capoccia D, Leonetti F, et al. (2011) Tenyear duration of type 2 diabetes as prognostic factor for remission after sleeve gastrectomy. Surg Obes Relat Dis. 7: 697-702.

32. NICE (2015) The management of Type 2 Diabetes. CG87.

33. Blackstone R, Bunt JC, Cortés MC, Sugerman HJ (2012) Type 2 diabetes after gastric bypass: remission in five models using $\mathrm{HbAlc}$, fasting blood glucose, and medication status. Surg Obes Relat Dis. 8: 548-55.

34. Hayes MT, Hunt LA, Foo J, Tychinskaya Y, Stubbs RS (2011) A model for predicting the resolution of type 2 diabetes in severely obese subjects following Roux-en Y gastric bypass surgery. Obes Surg. 21: 910-6.

35. Robertson PR, Harmon J, Tran PO, Poiout V (2004) Beta-cell glucose toxicity, lipotoxicity, and chronic oxidative stress in type 2 diabetes. Diabetes. 53: S119-24.

36. Cernea S, Dobreanu M (2013) Diabetes and beta cell function: from mechanisms to evaluation and clinicalimplications. Biochemia Medica. 23: $266-80$.

37. Georges E (2014) C-peptide. Medscape.

38. Tricia A (2009) C-peptide: Role in diabetes, insulinoma and hypoglycaemia. Diagnostic trends.

39. Ramos-Levi AM, Matia P, Cabrerizo L, Barabash A, Sanchez-Pernaute A et al. (2014) Statistical models to predict type 2 diabetes remission after bariatric surgery. J Diabetes. 6: 472-7.

40. Aarts EO, Janssen J, Janssen IM, Berends FJ, Telting D, et al. (2013) Preoperative fasting plasma C-peptide level may help to predict diabetes outcome after gastric bypass surgery. Obes Surg. 23: 867-73.

41. Ugale S, Gupta N, Modi KD, Kota SK, Satwalekar V, et al. (2014) Prediction of remission after metabolic surgery using a novel scoring system in type 2 diabetes - a retrospective cohort study. J Diabetes Metab Disord. 13: 89.

42. Lee W-J, Almulaifi A, Tsou J, Ser K-H, Lee Y-C, et al. (2015) Laparoscopic sleeve gastrectomy for type 2 diabetes mellitus: predicting the success by $\mathrm{ABCD}$ score. Surgery for Obesity and Related Disease.

43. Lee WJ, Hur KY, Lakadawala M, Kasama K, Wong SK, et al. (2013) Predicting success of metabolic surgery: age, body mass index, C-peptide, and duration score. Surg Obes Relat Dis. 9: 379-84. 